\title{
Evaluation of the Effectiveness of the Logistics System
}

\author{
Polina Arshinina* Albina Kiseleva
}

\author{
Department of Regional Economy and Territory, F.M. Dostoevsky Omsk State University, Omsk 644077, Russia \\ *Corresponding author. Email: arshinina.polina@gmail.com
}

\begin{abstract}
Nowadays, there is no universal method for measuring the effectiveness of the logistic system, which takes into account its dynamics and the whole variety of alternatives determining the processes occurring in it. This article presents the result of scientific research on the effectiveness of logistics system. The logistics costs or profit, which is formed during the promotion of material flows, can be defined as one universal parameter with which the effectiveness of the whole logistics system. The analysis of the regional practices in logistics shows that there are five key indicators of system's effectiveness such as the aggregate logistical costs, the quality level of the logistics service, the overall performance of the business system, the total duration of the logistic processes in the system and the quality of logistics operations.
\end{abstract}

Keywords: logistics, supply chain, management, system

\section{INTRODUCTION}

In today's highly competitive global marketplace, the pressure on companies to find new ways to create value and to deliver it to their customers grows ever stronger. The increasing need for industry to compete with its products in a global market across cost, quality and service dimensions has given rise to the need to develop more efficient logistics system. The efficient management of logistics helps to optimize the existing production and distribution processes and greatly assist in the goal of the cost reduction and service enhancement [1]. The evaluation of the effectiveness of the logistics system plays a major role in the success of the physical distribution of products and smoothly running businesses. These issues were repeatedly considered by Mentzer, el al. [2], M. Christopher [3], J. Holmström, J. Partanen, J. Tuomi and M. Walter [4], K. Oettmeier and E. Hofmann [5] , T. Sadraoui and N. Mchirgui [6], H. Treiblmaier H. [7], Verboeket V. and Krikke H. [8], etc. Companies that can manage their performance of the supply chains thought about chain as a whole and sought results shown in the revenue growth, asset utilization and cost reduction, in other words, the strategic themes [9]. Therefore, the purpose of the study is to identify the effectiveness and efficiency of the logistics and to investigate how both these components effect on company's region or international performances according to the business specific.

\subsection{Paper structure}

The paper is organized as follows. Section 1 introduces the evaluation of the concepts of logistics system's design and effectiveness, the data analysis of the effectiveness of the logistics system in Russia. The next section presents the contribution of this research. Finally, there are the conclusion and reference list.

\subsubsection{Concepts of logistics system design and effectiveness}

To begin with, a frequent problem of the logistics system design is that projects are undertaken piecemeal, without an organized framework for analysis. Consequently, systems, which are too complex or too inflexible to change as the market and the environment changes, are developed. The purpose of a logistics system is clear: to obtain and effectively move supplies and equipment in a timely fashion to the places where they are needed at a reasonable cost [10]. However, the equipment and supplies usually cannot go directly from their source to the end user, thus the inventory has to be held at one or more intermediate points along the way. There is a number of reasons for holding inventory, such as transportation efficiency, safety stocks, storage capacity and anticipation [1].

A logistics system's physical structure consists of the stationary facilities and the transportation links between those facilities. The facilities that are outside the system from which commodities are supplied are called sources. Facilities that receive supplies from a source are named primary supply points. Facilities, which dispense commodities to end users, are outlets [1]. It is important to evaluate a number of links into each facility, thus the more links there are, the more confused the system is likely to be. The essential questions in understanding the management structure of the logistics systems are - who decides what, when and how many commodities move through a link from one facility to the next, and how it will be decided?

There are two general types of the logistics systems: the allocation ("push") systems and the requisition ("pull") systems. In an allocation system, the higher-level facility decides what commodities and when move down the system. In a requisition system, the lower-level facility orders commodities as the need arises [11]. The advantages of the requisition systems are based on current information 
about actual needs, and thus, in theory, more accurate and less wasteful than the allocation systems. The requisition systems will work only if the accurate information about needs exists or can be obtained, and if lower level staff have sufficient management trainings and support to make appropriate decisions about the ordering. Allocation systems are, therefore, appropriate when accurate information on needs is not available or where management skill is concentrated at higher levels of the service system. If demand significantly exceeds supply, an allocation system must be used to divide scarce commodities among competing facilities.

Besides, the management structure of logistics may vary at different levels of the system; higher levels may requested and then allocate to lower levels. Even at a single level, the system may be mixed. In addition to the question of who makes the right decisions to move commodities, the achievement of the logistics effectiveness is substantial and should be based on the forecasting or quantification. It is important to note that an adequate forecasting process must consider of historical data, future program plans and underlying assumptions.

As the earlier discussion implies, only three things happen in a logistics system: commodities move down through the system, commodities are held in inventory at various points, and commodities are dispensed to users for subsequent consumptions [1]. Accordingly, there are three different types of records in the logistics information system, which are used in the forecasting and resupply decisions: the stock keeping records that include inventory control cards, the transaction records and the consumption records [1].

To sum up, there are a number of elements, which are required for effective logistics systems. The first is the technical data that consists of technical or scientific information or publications and that are also necessary to support, maintain and operate the system. The next element is personnel, that helps to identify and get employees with the grades and skills required to operate, support and maintain the system throughout its lifecycle. The "facilities" element includes locations, utilities, real restate requirements, space needs, equipment and environmental requirements. Another important element is the packaging, handling, storage and transportation (PHST) system that identifies all resources, procedures, processes, methods and design considerations to ensure all equipment, support items and systems are properly preserved, handled, packaged and transported correctly. Also, the important element is the implementation of active training programs for staff of the company that include whole crew and individual training, logistics support planning and new equipment training. Next element is the logistics-related design parameters such as availability of human factors, its survivability and reliability, meeting the resource requirements to minimize support and maximize readiness. In addition, the computer resources are required to support and operate the computer software within the system. The maintenance planning and analysis establishes are the required elements of the repair and maintenance support capabilities for restoring and maintaining the operational equipment. The "supplies" element consists of the identifying management actions, techniques and procedures necessary to acquire, store, issue and dispose of secondary items. This includes provisioning for initial support, procuring, and replenishing inventory parts. The last element is the support equipment that consists of the identification of fixed or mobile required equipment for the performing support functions, effective maintenance and operation of the systems.

\subsubsection{The effectiveness of the logistics system}

As it is known, every logistics operation is necessarily accompanied by the costs incurred by specific elements of the logistics system. Generally, the evaluation of the effectiveness of the logistics system can be carried out through a comparison of profits and costs that arise in the supply chain.

The key performance indicators of any logistics system are the aggregate logistical costs, the quality level of the logistics service, the overall performance of the business system, the total duration of the logistic processes in the system and the quality of logistics operations and processes (the level of logistics services) [12]. These indicators are used in the comparative assessment of companies and their logistics systems and should be easily measurable, thus they are the basis of the operational, tactical and strategic planning of modern companies and the monitoring of the efficiency of the logistics system and the management accounting system of the company.

The total logistic costs are the sum of the costs that arise in managing and implementing of all the processes and operations associated with the activities of the logistics systems, which can be divided into three groups: operating logistics costs (the cost of performing logistic operations), costs associated with managing the logistics system (administrative costs) and costs associated with the implementation of possible logistics risks [13].

The general classification of logistics costs by functional areas of logistics includes the costs of transportation (transportation costs), the storage costs, the costs associated with the processing and processing of goods, the costs of inventory management, the order management costs, the costs associated with the operation of logistics information systems, the costs of the stock's formation and maintenance of raw materials and finished products and the possible damages costs from the manifestation of the logistics risks or insufficient quality of logistics services.

Also, it is necessary to evaluate the quality of logistics services, which is assessed directly during its provision and to build it on the high level and regarding to the potential consumer's needs. Thus, the quality of logistics services can be defined as the degree of the compliance between the expectations of consumers of logistics services and the actual level of these service's provision, which is expressed through the perception of a set of quality criteria such as the physical environment of the service, the client behaviour, the logistics service provider reliability, responsibility, completeness and security [12]. 
Meanwhile, another important indicator of logistics effectiveness is the duration of the logistics processes in the system, which is the total lead time in the logistics system. The overall performance of the logistics system is characterized by an indicator of the volume of logistics services performed per unit of time in a given logistics system. It can be argued that it is necessary to represent the logistics system as an organizational and management complex aimed to achieve an effective balance between the logistics costs and an acceptable level of customer service quality of the logistics system. In this aspect, any logistics system can be interpreted as a system with effective feedback [1].

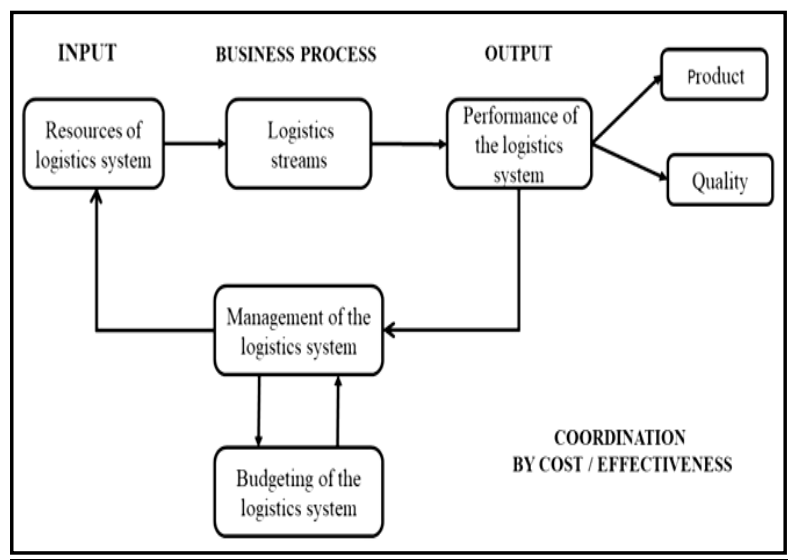

Figure 1 The logistics system as a system with efficient feedback
As it can be seen from the Figure 1 [14] above, the inputs are the resources of the logistics system and the outputs of the logistics system presents the results and the quality of logistics services, depend on their structure, quantity and composition. Thus, in order to formalize the procedure of the evaluation of the logistics effectiveness, it is necessary to look at the accuracy of the time and the place of delivery, the accuracy of range and quantity of products supplied, the accuracy of quality indicators supplied products and the compliance with the price requirements on the market.

\subsubsection{Data analysis of the effectiveness of the logistics system in Russia}

This analysis of the effectiveness of the logistics system is presented on the data materials of Russia. At first, it is necessary to look at the transport turnover in Russia in recent years.

As can be seen from the Table 1 [15] below, the transport turnover in Russia in January-February 2019, according to preliminary data, amounted to 920 billion ton-kilometers, including rail - 419,8 billion, automobile - 36,3 billion, sea $-5,8$ billion, inland water - 4 billion, air - 0,9 billion and pipeline $-453,1$ billion ton-kilometers. Thus, the pipeline and rail transport are the priority and more effective types of transport development in Russia. This is due to the size and the length of the country, its borders and the logistics structure. In addition, the rail, air and automobile transport modes are more suitable for the effective operation of the logistics systems, and customer's satisfaction and rapid response on their needs.

Table 1 The transport turnover by transport mode in Russia

\begin{tabular}{|c|c|c|c|c|c|}
\hline & \multirow{2}{*}{$\begin{array}{c}\text { February of } 2019 \\
\text { year, billion tons-km }\end{array}$} & \multicolumn{2}{|c|}{ In \% to } & \multicolumn{2}{|c|}{ February of 2018 year in \% to } \\
\hline & & $\begin{array}{c}\text { February of } \\
2018 \text { year }\end{array}$ & $\begin{array}{c}\text { January of } \\
2019 \text { year }\end{array}$ & $\begin{array}{c}\text { February of } \\
2017 \text { year }\end{array}$ & $\begin{array}{l}\text { January of } \\
2018 \text { year }\end{array}$ \\
\hline Total transport turnover & 438,4 & 101,7 & 91,0 & 102,1 & 91,7 \\
\hline \multicolumn{6}{|c|}{ including by transport mode } \\
\hline - rail & 199,4 & 101,3 & 90,4 & 103,8 & 91,3 \\
\hline - automobile & 18,2 & 100,2 & 99,9 & 103,3 & 104,6 \\
\hline - sea & 2,7 & 86,2 & 88,6 & 124,5 & 103,9 \\
\hline - inland water & 2,2 & 136,3 & 122,6 & 101,6 & 91,3 \\
\hline - air & 0,4 & 86,3 & 85,3 & 99,3 & 80,5 \\
\hline - pipeline & 215,5 & 102,2 & 90,7 & 100,1 & 90,9 \\
\hline
\end{tabular}

The data at Table 2 [15] represents the stable situation in Russian transport turnover in recent years. The reasonable increase of the transport turnover's dynamics can be noted in Russia in every quarter of 2018 year and at the beginning 
of 2018 year. In addition, since 2016 the conveyance of goods by the transport mode shows the growth trend in Russia. That can be seen at Table 3 [16]. The scale of good's conveyance by transport mode increases constantly every year and becomes a typical effectiveness indicator applicable to logistics processes. This tendency indicates the stable development of the whole country, the effectiveness and the reliability of the whole logistics system in 2018-2019, that are important for the overall performance of the business system, the total duration of the logistic processes in the system and the quality of logistics operations.

Table 2 Dynamics of the transport turnover in Russia 2018-2019

\begin{tabular}{|c|c|c|c|}
\hline \multirow[t]{2}{*}{ Period } & \multirow{2}{*}{$\begin{array}{c}\text { February of } 2019 \\
\text { year, billion tons-km }\end{array}$} & \multicolumn{2}{|c|}{ In \% to } \\
\hline & & February of 2018 year & February of 2018 year \\
\hline 1st quarter of 2018 year & 1383,7 & 102,5 & 97,2 \\
\hline 2nd quarter of 2018 year & 1390,8 & 103,4 & 100,5 \\
\hline 3rd quarter of 2018 year & 1409,4 & 102,9 & 101,3 \\
\hline 4th quarter of 2018 year & 1456,1 & 102,3 & 103,3 \\
\hline Total 2018 year & 5640,0 & 102,8 & \\
\hline January of 2019 year & 481,6 & 102,4 & 97,8 \\
\hline February of 2019 year & 438,4 & 101,7 & 91,0 \\
\hline January \& February of 2019 year & 920,0 & 102,1 & \\
\hline
\end{tabular}

Table 3 The conveyance of goods by transport mode in Russia

\begin{tabular}{|l|c|c|c|}
\hline \multirow{2}{*}{} & \multicolumn{3}{|c|}{ In million tons per year } \\
\cline { 2 - 4 } & $\mathbf{2 0 1 5}$ & $\mathbf{2 0 1 6}$ & $\mathbf{2 0 1 7}$ \\
\hline Transport - total & 7898 & 7954 & 8071 \\
\hline including by transport mode: & 1325 & 1384 \\
\hline$\bullet \quad$ railways & 1329 & 5397 & 5404 \\
\hline$\bullet \quad$ road & 5357 & 1088 & 1138 \\
\hline$\bullet \quad$ pipeline & 1071 & 25 & 25 \\
\hline$\bullet \quad$ maritime & 19 & 118 & 119 \\
\hline$\bullet \quad$ inland water & 121 & 1,1 & 1,3 \\
\hline
\end{tabular}

To sum up the statistical data, the effectiveness of the logistic systems of companies is various in the different regions of Russia, thus it is related to the number of factors such as the economic situation, the transport systems and the availability of the connections between regions, the government support and market's competitions. Thus, it is important to provide the proper analysis of the logistics systems effectiveness at the company, but also in regions and whole country in order to achieve the effective business structures and supply chains on the local, region and international marketplaces.

\section{OUR CONTRIBUTION}

This paper presents the most common, typical indicators of the effectiveness evaluating of logistic system and business processes. These indicators are characterizing the capacity, productivity, and costs of the enterprise's logistics system. On one hand, our optimization is the verification of the role of the logistics system's efficiency, which is determined by the level of quality of service. Also, the determination of the logistics costs and its analysis can allow to increase the profit and the financial capacity of the economic entity.

\section{CONCLUSION}

The effectiveness of the logistics system is determined by the availability of stocks, productivity and quality of activities. The total cost of logistics is in direct connection with the desired level of the performance. As a rule, the higher this level, the greater the total costs of logistics. The key to creating an efficient logistics system at an enterprise is the ability to maintain a balance between the level of logistics services and the total costs.

From the consumer's point of view, the efficiency of the logistics system is determined by the level of quality of service of its order. Logistics costs act as a tool for enterprise management. The determination of the logistics costs composition contributes to making economically sound management decisions. The analysis of such costs 
Development, vol. 2(2), International Journal of Econometrics and Financial Management, 2014, pp. 5971. DOI: https://doi.org/10.12691/ijefm-2-2-2

[7] H. Treiblmaier, The impact of the blockchain on the supply chain: a theory-based research framework and a call for action, vol.23(6), Supply Chain Management: An International Journal, 2008, pp. 545-559. DOI: https://doi.org/10.1108/scm-01-2018-0029

[8] V. Verboeket, H. Krikke, H. (2019). Additive Manufacturing: A Game Changer in Supply Chain Design, vol. 3(2), Logistics, 2019, pp. 13. DOI: https://doi.org/10.3390/logistics3020013

\section{REFERENCES}

[1] A. Rushton, P. Croucher, P. Baker, The Hand Book of Logistics \& Distribution Management (5th ed.), London: Kogan Page, 2014.

[2] J.T. Mentzer, W. Dewitt, J. S. Keebler, S. Min, N. W. Nix, C. D. Smith, Z. G. Zacharia, Defining Supply Chain Management, vol. 22(2), Journal of Business Logistics, 2001, pp. 1-25. DOI: https://doi.org/10.1002/j.2158-1592.2001.tb00001.x

[3] M. Christopher, Logistics and Supply Chain Management: Strategies for Reducing Cost and Improving Service (Second Edition), vol.2(1), International Journal of Logistics Research and Applications, 1999, pp. 103-104. DOI: https://doi.org/10.1080/13675569908901575

[4] J. Holmström, J. Partanen, J. Tuomi, M. Walter, Rapid manufacturing in the spare parts supply chain, vol. 21(6), Journal of Manufacturing Technology Management, 2010, pp. 687-697. DOI: https://doi.org/10.1108/17410381011063996

[5] K. Oettmeier, E. Hofmann, Impact of additive manufacturing technology adoption on supply chain management processes and component, vol. 27(7), Journal of Manufacturing Technology Management, 2016, pp.944-968. DOI: https://doi.org/10.1108/jmtm12-2015-0113

[6] T. Sadraoui, N. Mchirgui, Supply Chain Management Optimization within Information System
[9] J.D. Pagh, M. Cooper, Supply Chain Postponement and Speculation Strategies: How to Choose the Right Strategy, vol. 19(2), Journal of Business Logistics, 1998, pp. 13-33.

[10] D. Hall, R. Jones, C. Raffo, A. Anderton, I. Chambers, D. Gray, Business studies: Teachers guide (4th ed.), Harlow, Essex: Pearson Education, 2008.

[11] R. C. Owens, Jr.T. Warner, Concepts of Logistics System Design, Arlington, Va.: John Snow, Inc./DELIVER, for the U.S. Agency for International Development (USAID), 2003.

[12] A.P. Tyapuhin, Designing commodity distribution systems based on logistics: studies allowance, Moscow: Finance and Statistics, 2007.

[13] L. B. Mirotin, Logistics: customer service: a textbook. Moscow: INFRA, 2002.

[14] D. Kosten, ECR. Effective interaction with the consumer, Moscow: Publishing house KIA-Center, 2006.

[15] The Transport, The Freight transportation. In January-February 2019 (Rep.), Moscow, Russian Federation: Federal State Statistics Service, 2019. http://www.gks.ru/wps/wcm/connect/rosstat_main/rosst at/ru/statistics/enterprise/transport/

[16] Russian statistical yearbook, Moscow, Russian Federation: Federal State Statistics Service, 2018. http://www.gks.ru/bgd/regl/b18_13/Main.htm 